\title{
EXPERIMENTAL STUDY ON THE SHEAR BEHAVIOR OF FRCM STRENGTHENED MASONRY PANELS
}

\author{
FRANCESCA FERRETTI $^{1 *}$, ANDREA INCERTI ${ }^{2}$ AND CLAUDIO MAZZOTTI $^{1}$ \\ ${ }^{1}$ Department of Civil, Chemical, Environmental and Materials Engineering (DICAM) \\ University of Bologna \\ Viale Risorgimento 2, 40136 Bologna, Italy \\ e-mail: francesca.ferretti10@unibo.it (*corresponding author), claudio.mazzotti@unibo.it \\ ${ }^{2}$ CIRI Buildings and Construction (CIRI-EC) \\ University of Bologna \\ Via del Lazzaretto 15/5, 40131 Bologna, Italy \\ e-mail: a.incerti@unibo.it
}

Keywords: Masonry, In-plane Shear Behavior, Brick, FRCM, Strengthening

\begin{abstract}
Innovative strengthening solutions, such as Fiber Reinforced Cementitious Matrix (FRCM), are becoming increasingly diffused for the retrofitting of existing masonry structures with the aim of reducing the seismic vulnerability of these construction typologies. In recent years, many studies have demonstrated the suitability of these materials in enhancing the shear capacity of masonry walls and improve the overall structural behavior, avoiding fragile collapse mechanisms. In the present work, six diagonal compression tests were performed on unstrengthened and FRCM strengthened masonry panels to evaluate the improvements attributable to the presence of the FRCM systems. Two different bidirectional basalt grids were applied to the masonry samples, with and without mechanical anchorages. The tensile and bond properties of the chosen FRCM systems were investigated through laboratory tests. The objective was, indeed, to compare the performances of two textiles, characterized by different densities, and to investigate the role of mechanical anchorages. The experimental results confirmed the efficiency of the FRCM strengthening systems in improving the shear behavior of masonry panels. The FRCM strengthened samples experienced a considerable strength increase and less brittle failure mechanisms. The roles of both the mortar matrix, the fiber grids and the mechanical anchorages were highlighted by analyzing the onset of cracking and the failure propagation within the samples.
\end{abstract}

\section{INTRODUCTION}

The structural performances and the safety of historical masonry building during a seismic event are key aspects to be assessed, since these construction typologies usually show a weak behavior if subject to horizontal loads, characterized by out-of-plane and in-plane collapses $[1,2]$. Several researches in literature studied different retrofitting systems realized by using composite materials applied to the surface of masonry elements, in order to enhance the structural capacity with respect to the shear actions invoked during an earthquake without 
evident changes in stiffness.

In this framework, Fiber Reinforced Polymer (FRP) or Fiber Reinforced Cementitious Matrix (FRCM) systems were introduced and their advantages and drawbacks highlighted [35]. The behavior of these innovative materials was broadly analyzed with reference to the resistance, i.e. tensile and bond strength, the influence of the masonry substrate, e.g. presence of mortar joint and brick roughness, their compatibility with the substrate, the sustainability, and the fire resistance [6-13]. Studies were also carried out about the in-plane behavior of masonry walls, made of different masonry substrates, strengthened with composite materials [14-21]. From the structural point of view, the efficiency of these systems was found to be highly significant.

The aim of the present research is to enhance the knowledge about the structural performances and the failure modes of masonry panels, built with clay bricks and lime-based mortar, strengthened with FRCM systems made with bidirectional basalt fiber grids and a limebased mortar matrix. To this aim, a diagonal compression test setup [22,23] was adopted to analyze the in-plane shear behavior of the wall panels. The experimental results obtained were discussed in terms of load bearing capacity and maximum displacement at collapse, considering the effectiveness of the FRCM strengthening systems with respect to the unreinforced masonry samples.

\section{EXPERIMENTAL CAMPAIGN}

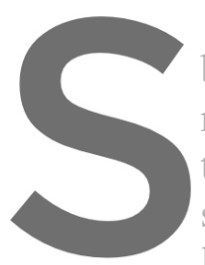

In the present expqrir

built with the same fire

masonry panel dimensi

the $B-M 1$ and $B-M 2$ typology,

substrate type. Subseque

lime-based mortar mattix and
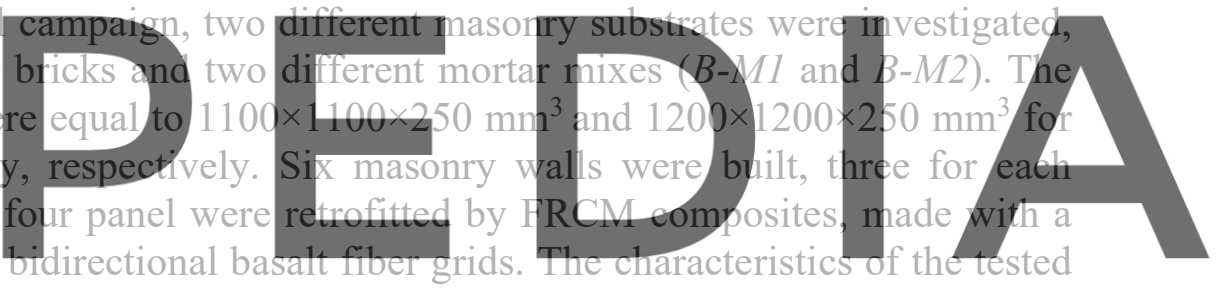

samples are reported in Table 1, where each specimen is named with a code indicating the wall

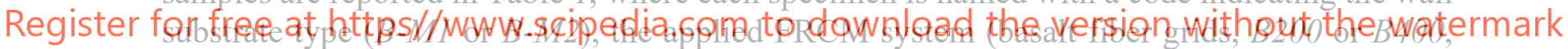

and mortar matrix type, M3 or M4) and the presence of mechanical anchorages (A) or not. A

continuous layout of the strengthening system was adopted (F igure 1): the bidirectional basalt grids were applied symmetrically on the entire surfaces of the wall panels, adopting an offset of about $20 \mathrm{~mm}$ from edges to prevent early debonding phenomena. A single grid layer per side was adopted, embedded in a $6 \mathrm{~mm}$ thick layer of mortar. A total number of six diagonal compression tests were performed. The mechanical characterization of the masonry components and the FRCM strengthening systems will be presented in the following Sections.

Table 1: Experimental campaign: characteristics of the tested samples

\begin{tabular}{lcc}
\hline Specimen ID & FRCM system & Mechanical Anchorages \\
\hline B-M1_URM & - & - \\
\hline B-M2_URM & - & - \\
\hline B-M1_B200-M3-A & & Yes \\
\cline { 1 - 1 } B-M2_B200-M4 & Basalt fiber grid + & - \\
\cline { 1 - 1 } B-M1_B400-M3-A & NHL mortar matrix & Yes \\
\cline { 1 - 1 } & & - \\
\hline
\end{tabular}




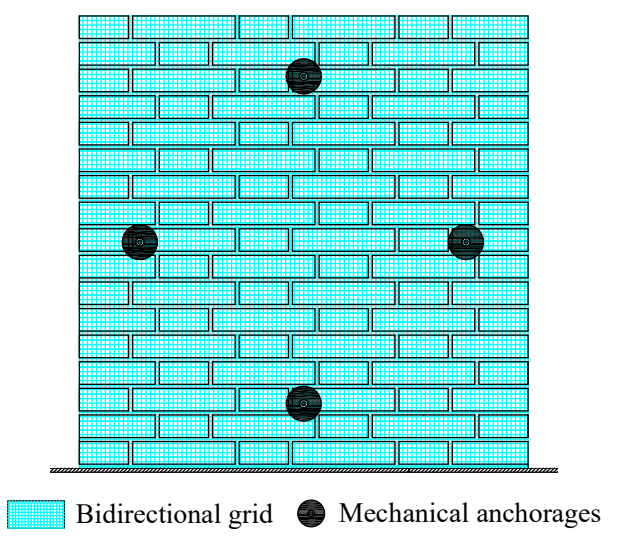

Figure 1: FRCM strengthening system layout

\subsection{Masomry constituents}

The fired clay bricks adopted for the construction of the masonry panels had dimensions equal to $120 \times 250 \times 55 \mathrm{~mm}^{3}$. Their mechanical properties were investigated through standard laboratory tests. In particular, uniaxial compressive tests [24] and Brazilian tests [25] were carried out on cylindrical specimens with a unitary aspect ratio, obtaining a compressive strength $f_{c, b}$ equal to $18.7 \mathrm{MPa}(\mathrm{CoV}=5 \%)$ and a tensile strength $f_{t, b}$ equal to $3.1 \mathrm{MPa}(\mathrm{CoV}=$

$15 \%)$. Moreover, three-points bending tests $[26]$ were performed on prismatic specimens,
having dimensions $40 \times 4.0 \times 250 \mathrm{~mm}^{3}$, for the evaluation of the flexural strength $f_{f l,}$, , obtaining
$4.8 \mathrm{MPa}(\mathrm{CoV}=7 \%)$. Finally, also the elastic modulus was deternined through cyclic
compression tests $[27]$, resulting to be equal to $6850 \mathrm{MPa}(\mathrm{CoV}=3.9 \%)$
Concerning the mortar used in the masonry bed joints, two mortar typologies were adopted
for the construction of the brick masonry pancts ( $M 1$ and $M 2)$. They were pre-mixed natural

hydraulic lime-based mortars and they were subject to standard laboratory tests for the

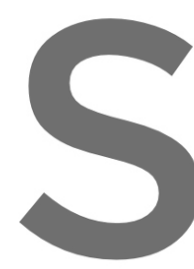

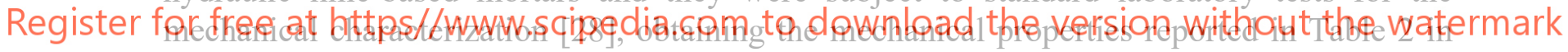
terms of compressive strength $\left(f_{c, m}\right)$, flexural strength $\left(f_{f t, m}\right)$ and elastic modulus $\left(E_{m}\right)$.

Table 2: Mechanical properties of the mortars

\begin{tabular}{lcccccc}
\hline Mortar & $f_{c, m}(\mathrm{MPa})$ & $\mathrm{CoV}(\%)$ & $f_{f l, m}(\mathrm{MPa})$ & $\mathrm{CoV}(\%)$ & $E_{m}(\mathrm{MPa})$ & $\mathrm{CoV}(\%)$ \\
\hline M1 & 4.8 & 12 & 1.5 & 15 & 4590 & 17 \\
M2 & 2.6 & 12 & 1.2 & 9 & 4250 & 18 \\
\hline
\end{tabular}

\subsection{Strengthening systems and layout}

Two different FRCM retrofitting systems were investigated, constituted of bidirectional symmetrical basalt fiber grids embedded in a natural hydraulic lime-based mortar matrix. The grids were characterized by different density, equal to $200 \mathrm{~g} / \mathrm{m}^{2}$ (B200) and $400 \mathrm{~g} / \mathrm{m}^{2}$ (B400), and equivalent thicknesses equal to $0.032 \mathrm{~mm}$ and $0.064 \mathrm{~mm}$, respectively. Pre-mixed natural hydraulic lime-based mortars were adopted as matrix (M3 and $M 4$ ), characterized by the mechanical properties reported in Table 3, evaluated through standard tests [28].

At the beginning of the experimental campaign, the adopted FRCM strengthening systems 
were subject to direct tensile tests in order to evaluate the tensile strength $f_{t, f}$, the ultimate strain $\varepsilon_{u}$ and the fiber elastic modulus $E_{f}$. Moreover, direct shear tests [6] were also performed to determine the bond strength $f_{b, f}$. The experimental outcomes of tensile and bond tests are reported in Table 4 and Table 5, respectively.

The efficiency $\eta$ of the basalt FRCM systems was evaluated as the ratio between the bond strength and the tensile strength (Table 5): the highest value (91\%) was associated to the textile failure due to fiber rupture (B200), while the lowest value $(64 \%)$ was observed for the textile showing a delamination at the matrix-fiber interface (B400).

Table 3: Mechanical properties of the mortar matrices

\begin{tabular}{lcccccc}
\hline Mortar & $f_{c, m}(\mathrm{MPa})$ & $\mathrm{CoV}(\%)$ & $f_{f, m}(\mathrm{MPa})$ & $\mathrm{CoV}(\%)$ & $E_{m}(\mathrm{MPa})$ & $\mathrm{CoV}(\%)$ \\
\hline M3 & 12.6 & 9 & 2.9 & 23 & 9100 & 14 \\
M4 & 13.1 & 5 & 3.4 & 5 & 8675 & 11
\end{tabular}

Table 4: FRCM systems: results of the tensile tests

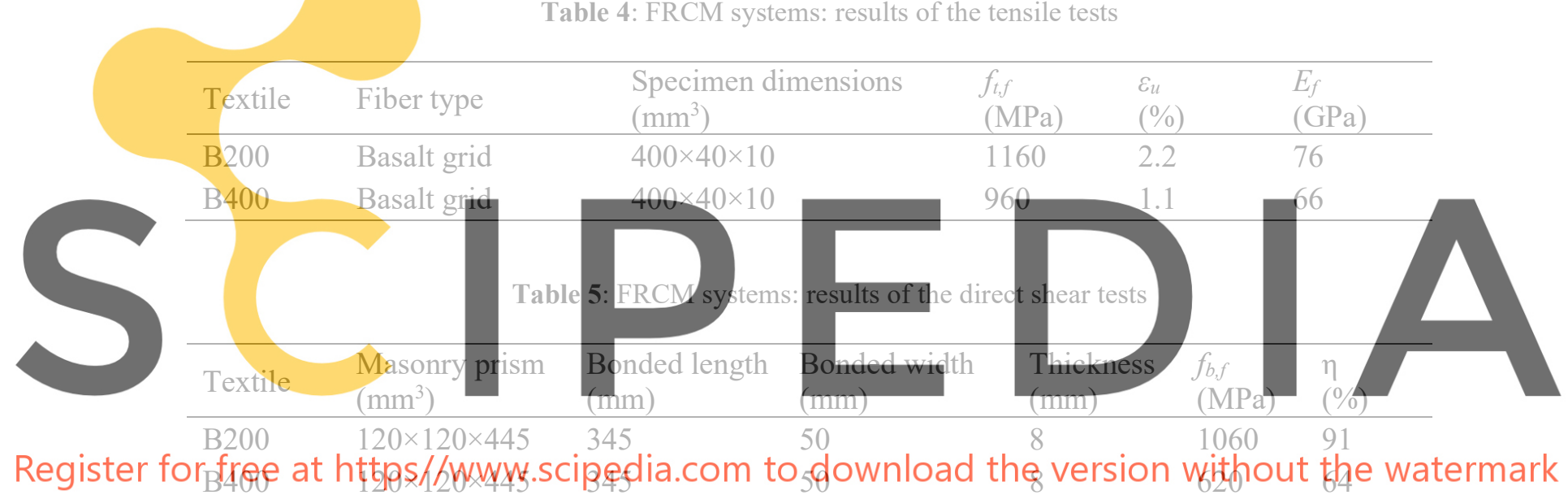

\section{DIAGONAL COMIPRESSION (DC) TEST SETUP}

The experimental setup used to evaluate the shear capacity of the clay brick masonry walls was a standard setup, following the indications provided by the ASTM E519 and RILEM LUMB6 Standards [22,23]. A servo-hydraulic actuator, equipped with a load cell having a maximum capacity of $500 \mathrm{kN}$, was used for the application of the diagonal compression displacement. The tests were, indeed, performed under displacement control with a rate equal to $0.01 \mathrm{~mm} / \mathrm{s}$ to analyze both the pre-peak and the post-peak behavior. The diagonal displacements were measured by four linear potentiometers $(50 \mathrm{~mm}$ stroke and $1100 \mathrm{~mm}$ gage length), positioned on both sides of the masonry panels along the two principal diagonals. The setup of the test is shown in Figure 2. In accordance with the elastic solution of a masonry panel subject to a DC test $[29,30]$, the stress state $(\sigma, \tau)$ in the center of the panel and the masonry tensile strength $f_{t}$ can be evaluated as: 


$$
\begin{gathered}
\sigma=0.56 \frac{P}{A_{n}} \\
\tau=1.05 \frac{P}{A_{n}} \\
f_{t}=0.5 \frac{P_{f}}{A_{n}}
\end{gathered}
$$

where $P$ is the diagonal load ( $P_{f}$ at failure) and $A_{n}$ is the net area of the wall. In this configuration, the directions of the principal stresses are known and coincident with the diagonals of the panels. The shear strain $\gamma$ can be determined as the sum of the deformations evaluated along the principal directions $\left(\varepsilon_{c}\right.$ and $\left.\varepsilon_{t}\right)$, taken as the average between the deformations on the two sides of the specimen. Considering the tangential stress $\tau$ vs shear strain $\gamma$ diagram, the shear modulus $G$ can be evaluated as the secant modulus between $1 / 10$ and $1 / 3$ of the maximum tangential stress.
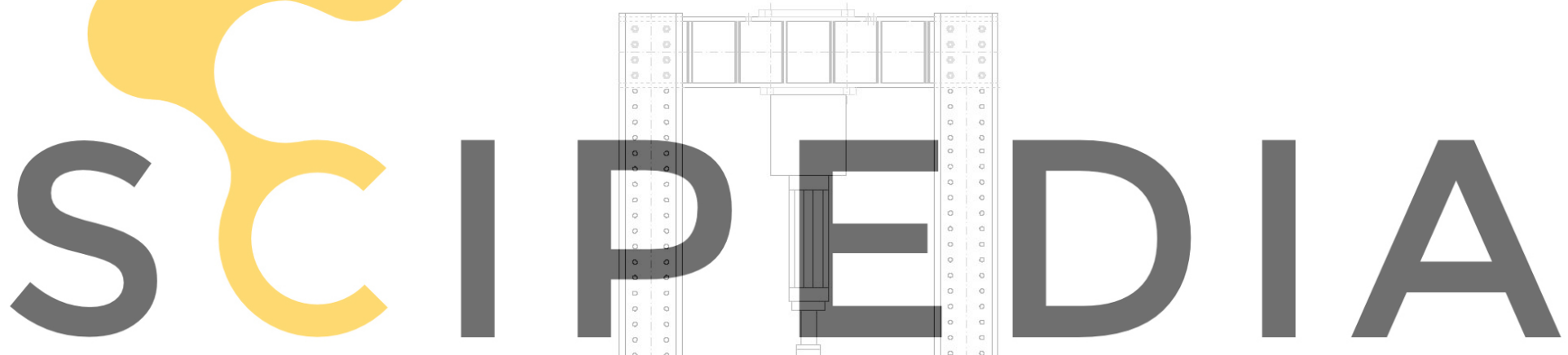

Register for free at https//www.scipedia.com to download the version without the watermark

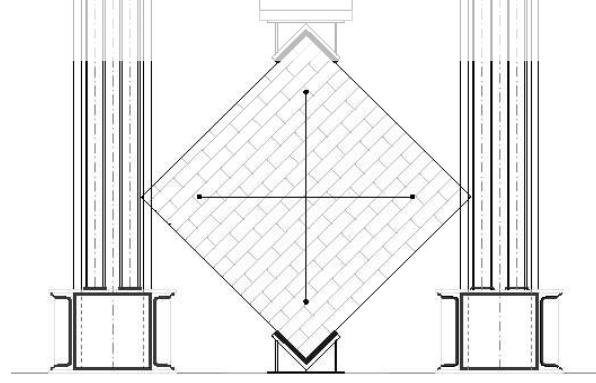

Figure 2: Diagonal compression (DC) test setup.

\section{EXPERIMENTAL RESULTS}

The experimental results are presented and discussed in this Section in terms of shear behavior, shear capacity and failure mode with the objective of discussing the improvements given by the FRCM composites applied on unreinforced masonry. 


\subsection{Failure modes}

During the DC tests, two different failure modes occurred, reported in Figure 5. In particular, the failure modes of the URM panels were characterized by an evident single fracture line along the compressed diagonal, according to the panel stress state (Figure 5a). The FRCM strengthened masonry walls, instead, showed a more widespread cracking pattern on the external surfaces of the reinforcing layers, along the compressed diagonal. With reference to the failure mode of the FRCM reinforcements, it was noticeable that the $B 200$ basalt grid (Figure $5 b, d$ ) was characterized by partial delamination and rupture of fibers along the cracking lines (Figure $5 f$ ), while the failure of the $B 400$ basalt grid was characterized by delamination phenomena only. This different behavior can be related to the reduced spacing of the $B 400$ grid, which did not allow the mortar matrix to properly penetrate within the grid itself. The presence of the mechanical anchorages did not significantly influence the overall behavior of the samples in terms of failure mode, but it prevented the grid detachment at the extremities of the wall panels, which was visible for the samples strengthened without the use of anchorages.

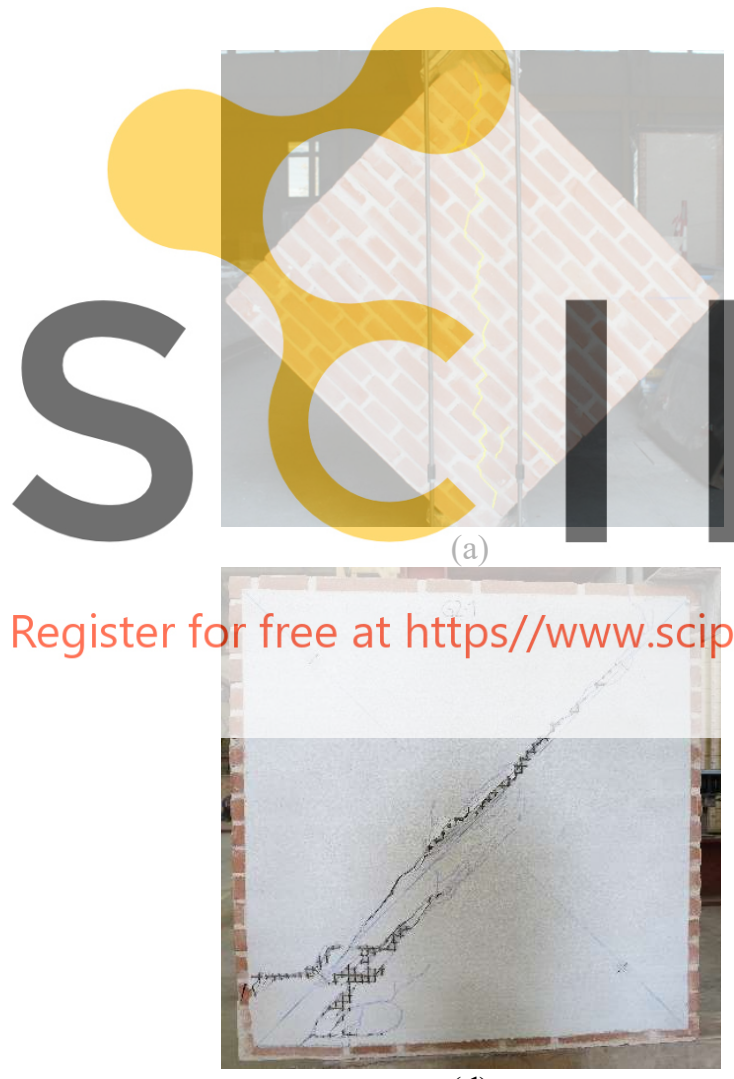

(d)
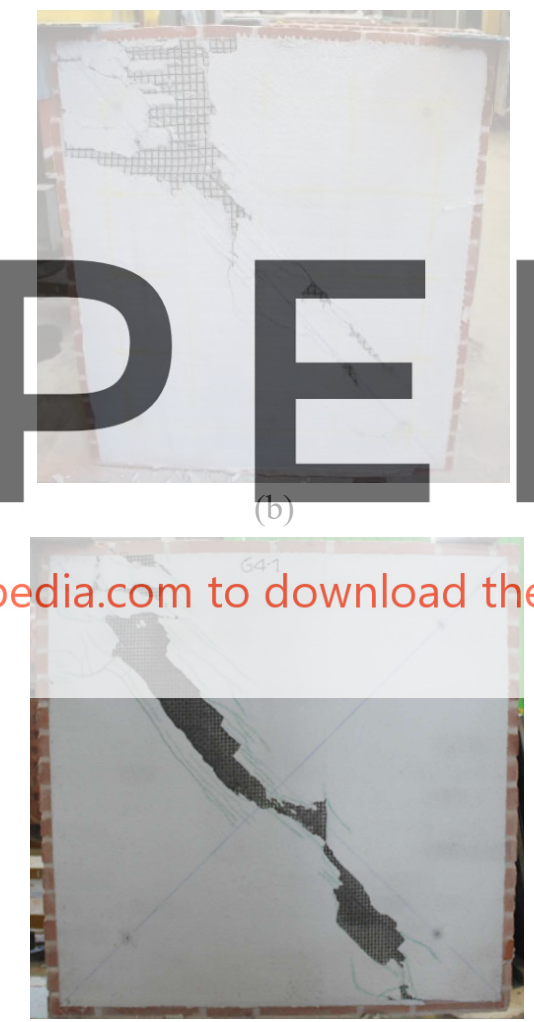

(e)

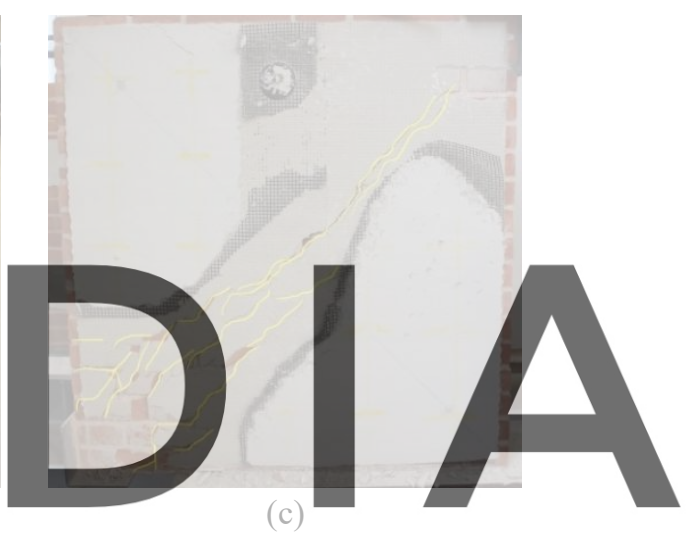

(c)

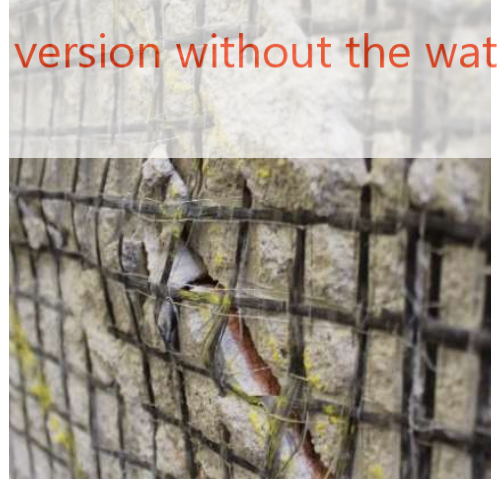

(f)

Figure 5: Failure modes in the DC tests: (a) URM panel; (b) B-M1_B200-M3-A; (c) B-M1_B400-M3-A; (d) BM2_B200-M4; (e) B-M2_B400-M4; (f) delamination and rupture of the $B 200$ textile. 


\subsection{Shear behavior and capacity of the FRCM strengthened panels}

The load $v s$ displacements graphs are reported in Figure 3 and Figure 4 for the $B-M 1$ and $B$ $M 2$ panel series, respectively. A very similar shear behavior was noticed, characterized by an initial linear branch and a first peak load, followed by a drop in the load bearing capacity and by a second peak load. From the experimental observations, it can be stated that the reaching of the first peak load corresponded with the appearance of the first crack in the mortar matrix. The second peak load, instead, can be associated with the failure of the textiles.

The results of the DC tests are summarized in Table 6 , in terms of diagonal load at failure $P_{f}$, strength increment with respect to URM panel, masonry tensile strength $f_{t}$, shear modulus $G$ and pseudo-ductility $\mu$. The latter was determined as the ratio between the ultimate shear strain, taken in correspondence of a $20 \%$ reduction in the load bearing capacity after the peak load, and the shear strain corresponding to the same load value along the initial loading branch.
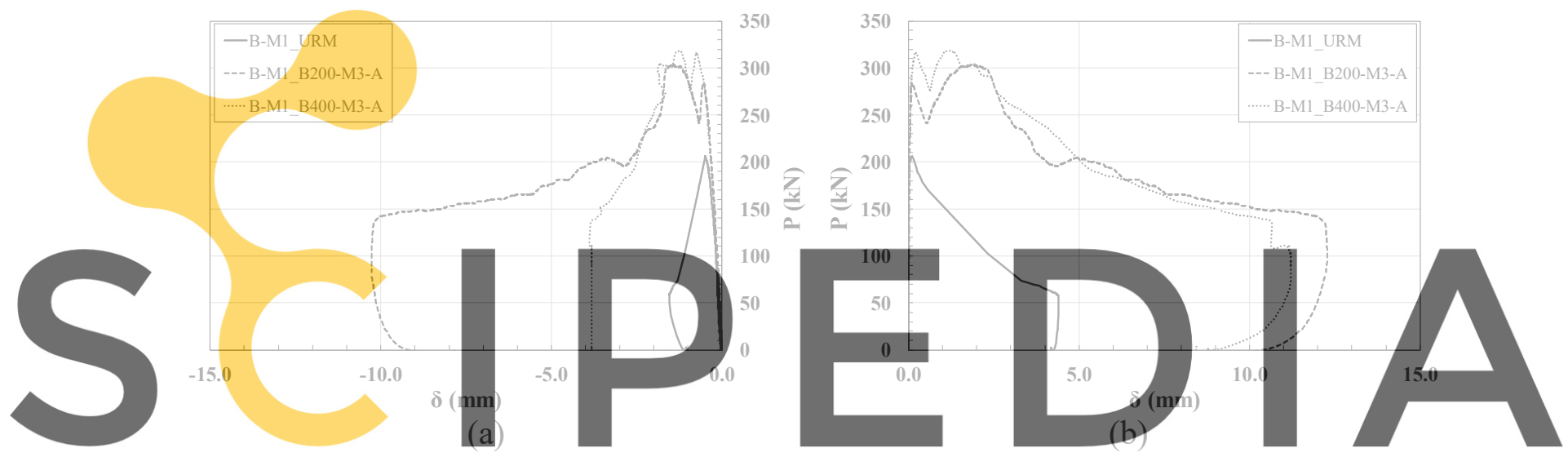

Figure 3: DC test results for B-MI panels: (a) Load vs vertical displacement graph; (b) Load vs horizontal Register for free at https//www.scipedia.copplatondowmload the version without the watermark

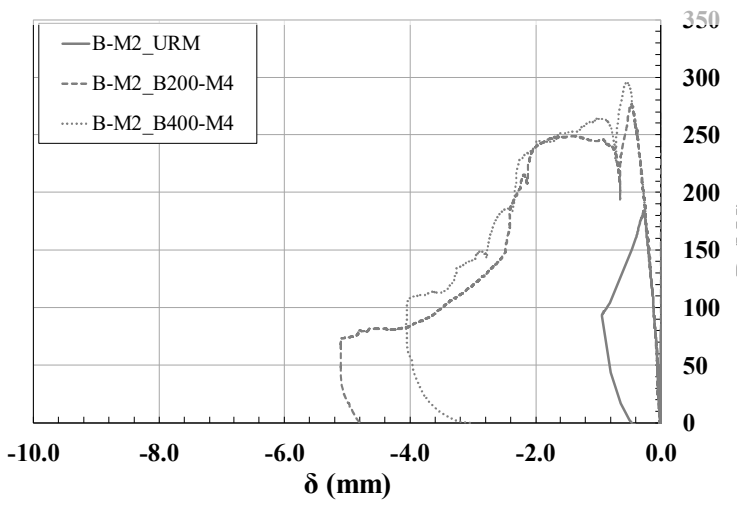

(a)

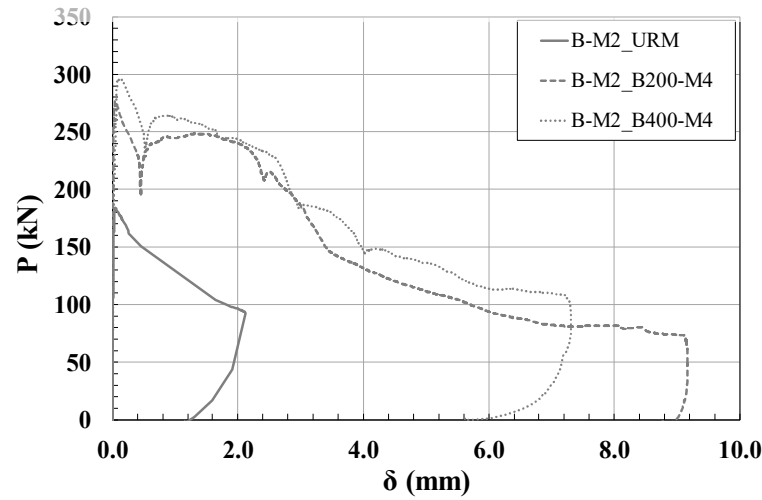

(b)

Figure 4: DC test results for $B-M 2$ panels: (a) Load $v s$ vertical displacement graph; (b) Load vs horizontal displacement graph 
Table 6: Diagonal compression test results.

\begin{tabular}{lllllll}
\hline $\begin{array}{l}\text { Sample } \\
\text { code }\end{array}$ & $\begin{array}{l}P_{f} \\
(\mathrm{kN})\end{array}$ & $\begin{array}{l}\text { Strength Increment } \\
(\%)\end{array}$ & $\begin{array}{l}\tau_{f} \\
(\mathrm{MPa})\end{array}$ & $\begin{array}{l}f_{t, M} \\
(\mathrm{MPa})\end{array}$ & $\begin{array}{l}\mathrm{G}_{1 / 10-1 / 3} \\
(\mathrm{MPa})\end{array}$ & $\begin{array}{l}\mu \\
(-)\end{array}$ \\
\hline B-M1_URM & 206.1 & - & 0.79 & 0.37 & 2660 & 4.0 \\
B-M2_URM & 183.7 & - & 0.64 & 0.30 & 3056 & 4.4 \\
B-M1_B200-M3-A & 303.7 & 47 & 1.16 & 0.55 & 2649 & 13.9 \\
B-M2_B200-M4 & 276.7 & 51 & 0.96 & 0.46 & 3216 & 13.3 \\
B-M1_B400-M3-A & 318.7 & 55 & 1.22 & 0.58 & 2810 & 10.9 \\
B-M2_B400-M4 & 295.8 & 61 & 1.04 & 0.49 & 2705 & 10.9 \\
\hline
\end{tabular}

With regards to the results obtained for the two URM panels, the differences observed in the maximum load and, consequently, in the masonry tensile strength, can be associated to the differences in the mechanical properties of the mortar used for the construction of the panels, e.g. $f_{c, m(B-M 1)}>f_{c, m(B-M 2)}$.

With reference to the results obtained for FRCM strengthened samples, it is possible to state that, for both the masonry typologies, significant strength increments were obtained. In particular, similar increments were observed for panels strengthened with the same FRCM system, given that the mortar matrices $M 3$ and $M 4$ were characterized by similar mechanical properties. It is worth mentioning that the strength increments obtained for the panels

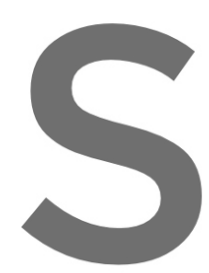
strengthened with the $B$ was characterized by an considered that the effic 5: the bond strength was approximately equa observation could expla B00 basa
amoun
sency of
approx
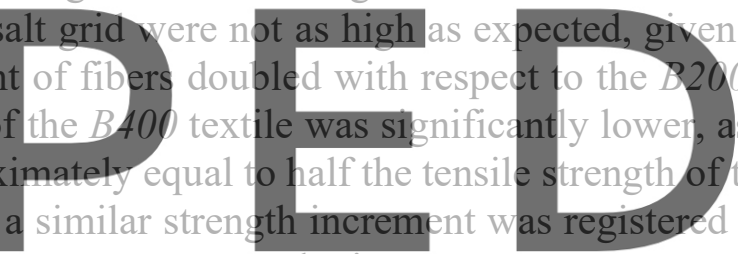
n that the
as report
f the $B 20$
d in the D

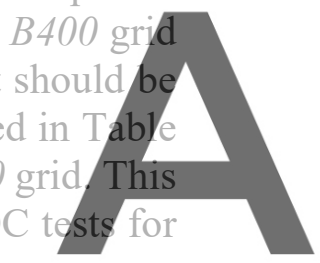
the panels strengthened with the two FRCM typologies.

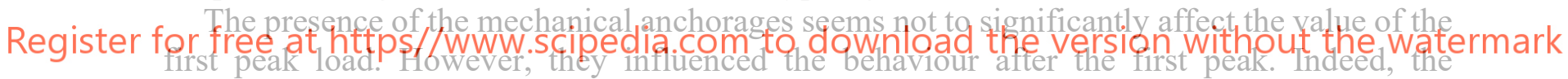
mechanical anchorages, and generally the fiber grids, started working in the second reloading branch. More in detail, the panels strengthened making use of anchorages experienced a higher load increment after the first peak, reaching a second peak load similar or even higher than the first one.

Values of the shear modulus $G$ for the masonry panels were quite similar, demonstrating that the structural performances were enhanced by the application of the FRCM retrofitting systems without considerable changes in terms of stiffness, with values ranging between 2649 and 3216 MPa.

Finally, the displacement capacity of the FRCM strengthened samples was significantly higher than the one of the URM samples, which experienced a quasi-brittle failure. Quite high values of the pseudo-ductility factor $\mu$ were, indeed, evaluated for all the FRCM strengthened panels. In particular, similar results were obtained for walls strengthened with the same FRCM system. The pseudo-ductility was higher for the panels strengthened by the $B 200$ textile, most probably for the same reasons introduced above: failure mode and efficiency of the grid. 


\section{ANALYTICAL FORMULATION}

The evaluation of the shear capacity of strengthened walls $\left(\tau_{t, r}\right)$ can be carried out through the anaytical formulation provided by the Italian CNR Guideline for the design of strengthening interventions using FRCM systems [31]. The formulation is based on an additive approach, considering the contributions of unreinforced masonry $\left(\tau_{f, U R M}\right)$ and of the dry fibers $\left(\tau_{t, f}\right)$, according to Equation (4):

$$
\tau_{t, r}=\tau_{f, U R M}+\tau_{t, f}=\tau_{f, U R M}+\frac{n_{f} \cdot t_{V f} \cdot l_{f} \cdot \alpha_{t} \cdot E_{f} \cdot \varepsilon_{f d}}{\gamma_{R d} \cdot A_{n}}
$$

where $\tau_{f}$ is here considered equal to the shear strength of the correspondent URM sample, $n_{f}$ is the number of reinforcing layers, $t_{v f}$ is the textile equivalent thickness, $l_{f}$ is the width of the FRCM system measured orthogonally to the shear force, $\alpha_{t}$ is a coefficient, equal to 0.8 , accounting for a reduced tensile strength for fibers subjected to shear, $E_{f}$ is the fiber elastic modulus, $\varepsilon_{f d}$ is the design strain of the FRCM system, $\gamma_{R d}$ is a safety factor, considered equal to 1 here, and $A_{n}$ is the net area of the panel cross section. In detail, the design strain is considered equal to the ratio between the bond strength and the elastic modulus $E_{f}$ of the dry fibers, for the panels strengthened without using mechanical anchorages, while it is multiplied by 1.5 for the panels reinforced with mechanical anchorages, to account for intermediate delamination phenomena.

The analytical and ex stress obtained in the strengthened walls, calc underestimates the exp between experimentaland analytical results. I
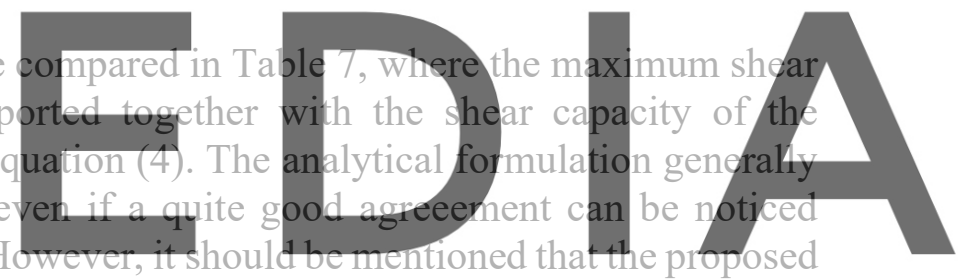
analytical formulation does not take into account the role of the mortar matrix, which was found

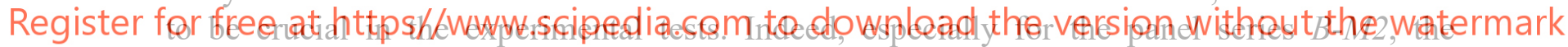
maximum shear stress was reached in correspondence of the first peak load, related to the cracking of the mortar matrix and not to the failure of the textile.

Table 7: Shear capacity of FRCM strengthened panels: analytical vs experimental results.

\begin{tabular}{llllll}
\hline $\begin{array}{l}\text { Sample } \\
\text { code }\end{array}$ & $\begin{array}{l}\tau_{f, U R M} \\
(\mathrm{MPa})\end{array}$ & $\begin{array}{l}\tau_{t, f} \\
(\mathrm{MPa})\end{array}$ & $\begin{array}{l}\tau_{t, r} \\
(\mathrm{MPa})\end{array}$ & $\begin{array}{l}\tau_{f, E x p .} \\
(\mathrm{MPa})\end{array}$ & $\begin{array}{l}\text { Error } \\
(\%)\end{array}$ \\
\hline B-M1_B200-M3-A & 0.79 & 0.31 & 1.10 & 1.16 & -5.2 \\
B-M2_B200-M4 & 0.64 & 0.21 & 0.85 & 0.96 & -11.5 \\
B-M1_B400-M3-A & 0.79 & 0.29 & 1.07 & 1.22 & -12.3 \\
B-M2_B400-M4 & 0.64 & 0.25 & 0.89 & 1.04 & -14.4 \\
\hline
\end{tabular}

\section{CONCLUSIONS}

The present research deals with the study of the shear behavior of FRCM strengthened 
masonry panels through the execution of DC tests. Six masonry panels were built, and two masonry typologies were considered. Four panels were then strengthened adopting two different FRCM systems, both characterized by the use of basalt bidirectional grids, having different densities, and a lime-based mortar matrix. The effect of the presence of mechanical anchorages on the shear strength of the masonry samples was also analyzed.

The experimental results showed a good efficiency of the strengthening systems, with strength increments ranging from $47 \%$ to $61 \%$, with respect to the URM panels. The presence of the FRCM systems did not determine significant stiffness increase of the panels but it influenced their failure mode, which became more ductile if compared to the quasi-brittle failure of the URM samples. The pseudo-ductility factor was indeed evaluated in the experimental campaign.

In general, the shear behavior of the FRCM strengthened samples was characterized by a first peak load, corresponding to the cracking of the mortar matrix, and by a second peak load, associated to the failure of the textiles. The role of the mortar matrix was highlighted since it was found to be crucial in the shear behavior of the strengthened panels. The presence of the mechanical anchorages seemed not to significantly affect the failure mode of the panels and the value of the first peak load. However, the anchorages allowed the textile to better redistribute the tensile stresses and determined a higher load increment after the drop in the load bearing capacity following the first peak load.

A comparison between the experimental results and the analytical formulation provided by the Italian CNR Guideline was carried out, showing a quite good agreement. In particular, the
analytical results tended to underestimate the experimental ones. In general, it should be analytical results tendet mentioned that the impo analytical formulation. contribution and mayb Further experimental
include it in an alterna
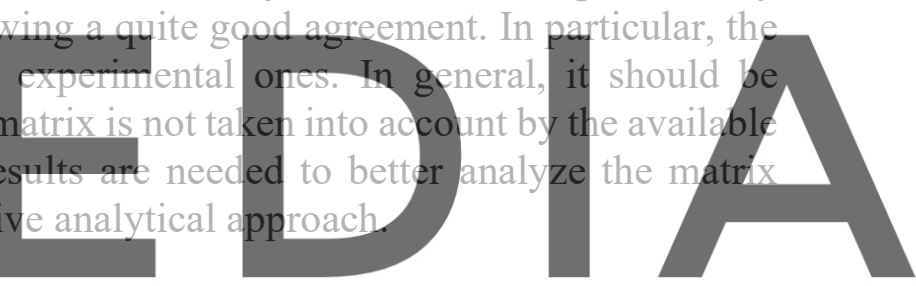

Acknowledgements. The financial and technical support of Kerakoll Spa, Sassuolo (MO) Italy,

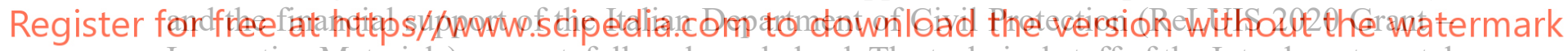
Innovative Materials) are gratefully acknowledged. The technical staff of the Interdepartmental Centre for Industrial Research (CIRI Buildings \& Construction) is gratefully acknowledged for the work during the setup of the tests.

\section{REFERENCES}

[1] Penna, A., Morandi, P., Rota, M., Manzini, C.F., da Porto, F. and Magenes G. Performance of masonry buildings during the Emilia 2012 earthquake. Bull. Earthq. Eng. (2014) 12:2255-73. https://doi.org/10.1007/s10518-013-9496-6.

[2] Ferretti, F., Ferracuti, B., Mazzotti, C. and Savoia M. Destructive and minor destructive tests on masonry buildings: Experimental results and comparison between shear failure criteria. Constr. Build. Mater. https://doi.org/10.1016/j.conbuildmat.2018.11.246.

[3] Papanicolaou, C., Triantafillou, T., Karlos, K. and Papathanasiou M. Textile-reinforced mortar (TRM) versus FRP as strengthening material of URM walls: in-plane cyclic loading. Mater. Struct. (2007) 40:1081-97. https://doi.org/10.1617/s11527-006-9207-8. 
[4] Papanicolaou, C., Triantafillou, T. and Lekka, M. Externally bonded grid as strengthening and seismic retrofitting materials of masonry panels. Constr. Build. Mater. (2011) 25(2):504-514.

[5] Mazzotti, C. and Murgo, F.S. Numerical and experimental study of GFRP-masonry interface behavior: Bond evolution and role of the mortar layers. Compos. Part B Eng. (2015) 75:212-225.

[6] De Felice, G., Aiello, M.A., Caggegi, C., Ceroni, F., De Santis, S., Garbin, E., et al. Recommendation of RILEM Technical Committee 250-CSM: Test method for Textile Reinforced Mortar to substrate bond characterization. Mater. Struct. (2018) 51:95. https://doi.org/10.1617/s11527-018-1216-X.

[7] Valluzzi, M.R., Oliveira, D.V., Caratelli, A., Castori, G., Corradi, M., de Felice, G., et al. Round Robin Test for composite-to-brick shear bond characterization. Mater. Struct. (2012) 45:1761-91. https://doi.org/10.1617/s11527-012-9883-5.

[8] Ceroni, F., de Felice, G., Grande, E., Malena, M., Mazzotti, C., Murgo, F., et al. Analytical and numerical modeling of composite-to-brick bond. Mater. Struct. (2014) 47:1987-2003. https://doi.org/10.1617/s11527-014-0382-8.

[9] de Felice, G., Aiello, M.A., Bellini, A., Ceroni, F., De Santis, S., Garbin, E., et al. Experimental characterization of composite-to-brick masonry shear bond. Mater. Struct. (2016) 49:2581-96. https://doi.org/10.1617/s11527-015-0669-4.

[10] Carozzi, F.G., Bellini, A., D’Antino, T., de Felice, G., Focacci, F., Hojdys, Ł., et al. Experimental investigation of tensile and bond properties of Carbon-FRCM composites for strengthening masonry elements. Compos. Part B Eng. (2017) 128:100-19. https://doi.org/10.1016/j.compositesb.2017.06.018.

[11] Sassoni, E., Andreotti, S., Bellini, A., Mazzanti, B., Bignozzi M.C., Mazzotti, C. and Franzoni E. Influence of mechanical properties, anisotropy, surface roughness and porosity of brick on FRP debonding force. Compos. Part B (2017) 108:257-269.

[12] Lignola, G.P., Caggegi, C., Ceroni, F., De Santis, S., Krajewski, P., Lourenço, P.B., Morganti, M., Papanicolaou, C., Pellegrino, C., Prota, A., and Zuccarino, L. Performance assessment of Basalt FRCM for retrofit applications on masonry. Compos. Part B (2017) 128:1-18.

[13] Bellini, A., Bovo, M. and Mazzotti, C. Experimental and numerical evaluation of fibermatrix interface behaviour of different FRCM systems. Compos. Part B (2019) 161:411426.

[14] Faella, C., Martinelli, E., Nigro, E. and Paciello, S. Shear capacity of masonry walls externally strengthened by a cement-based composite material: an experimental campaign. Constr. Build. Mater. (2010) 25:4403-4414.

[15] Babaeidarabad, S., De Caso, F. and Nanni, A. URM Walls Strengthened with FabricReinforced Cementitious Matrix Composite Subjected to Diagonal Compression. J. Compos. Constr. (2014) 18:04013045. https://doi.org/10.1061/(ASCE)CC.19435614.0000441.

[16] Ferretti, F., Incerti, A., Ferracuti, B. and Mazzotti, C. FRCM strengthened masonry panels: the role of mechanical anchorages and symmetric layouts. Key Eng. Mater. (2017) 747:334-341. 
[17] Incerti, A. Tilocca, A.R., Ferretti, F. and Mazzotti, C. Influence of masonry texture on the shear strength of FRCM reinforced panels. In: R. Aguilar et al. (Eds.): Structural Analysis of Historical Constructions, RILEM Bookseries 18 (2019), pp. 1623-1631.

[18] Ferretti, F., Incerti, A., Tilocca, A.R. and Mazzotti, C. In-Plane Shear Behavior of Stone Masonry Panels Strengthened through Grout Injection and Fiber Reinforced Cementitious Matrices. Int. J. Archit Herit. (2019). https://doi.org/10.1080/15583058.2019.1675803.

[19] Incerti A., Ferretti F. and Mazzotti C. FRCM strengthening systems efficiency on the shear behavior of pre-damaged masonry panels: an experimental study. J. Build. Pathol. Rehabil. (2019) 4:14. https://doi.org/10.1007/s41024-019-0053-9.

[20] Ferretti F., Incerti A., Ferracuti B., Mazzotti C. FRCM strengthened masonry panels: the role of mechanical anchorages and symmetric layouts. Key Eng. Mater. (2017) 747:334341.

[21] Del Zoppo M., Di Ludovico M., Prota A. Analysis of FRCM and CRM parameters for the in-plane shear strengthening of different URM types. Compos. B Eng. (2019) 171:20-33.

[22] ASTM E519-15. Standard test method for diagonal tension (shear) in masonry assemblages 2015:4-8. https://doi.org/10.1520/E0519.

[23] RILEM LUMB6. Diagonal tensile strength tests of small wall specimens. RILEM TC-76 $\operatorname{LUM}(1991)$.

[24] EN 772-1. Methods of test for masonry units - Part 1: Determination of compressive strength (2011).

[25] EN 12390-6:2009. Testing hardened concrete - Part 6: Tensile splitting strength of test specimen (2009).

[26] EN 12390-5:2009. Testing hardened concrete - Part 5: Flexural strength of test specimens (2009).

[27] EN 12390-13. Testing hardened concrete - Determination of secant modulus of elasticity in compression (2013).

[28] EN 1015-11:1999/A1:2006. Methods of test for mortar for masonry - Part 11: Determination of flexural and compressive strength of hardened mortar (2006).

[29] Frocht, M. Recent advances in photoelasticity. ASME Trans (1931) 55:135-53.

[30] Yokel, F.Y. and Fattal, S.G. A Failure hypothesis for masonry shearwalls. J. Struct. Div. - ASCE (1976) 102:515-32.

[31] CNR-DT 215/2018. Istruzioni per la Progettazione, l'Esecuzione ed il Controllo di Interventi di Consolidamento Statico mediante l'utilizzo di Compositi Fibrorinforzati a Matrice Inorganica (in Italian). National Research Council (CNR) (2018). 